\title{
The Diagnostic Value of Hysterosalpingography and Hysterolaparoscopy for Evaluating Uterine Cavity and Tubal Patency in Infertile Patients
}

\author{
Soumya R. Panda ${ }^{1}$, B Kalpana ${ }^{2}$ \\ 1. Obstetrics and Gynaecology, All India Institute of Medical Sciences, Mangalagiri, IND 2. Obstetrics and Gynaecology, \\ Guru Hospital, Madurai, IND
}

Corresponding author: Soumya R.Panda,drsome4141@gmail.com

\section{Abstract \\ Background and objective}

Hysterosalpingography (HSG) is a common radiologic modality employed for the initial workup of female infertile patients to evaluate for tubal patency or any gross intrauterine pathology. HSG is a relatively cheap and easily available outpatient procedure but bears the risk of radiation exposure. The purpose of the study was to compare the diagnostic value of HSG with that of diagnostic hysterolaparoscopy in infertile women and to evaluate their role in the diagnosis and management of infertility.

\section{Methodology}

This study was carried out from February 2018 to January 2019. All women attending our outpatient department (OPD) for the treatment of infertility who were aged between 20-40 years were included in the study. Those with acute vaginal and cervical infection and those having an allergic reaction to the dye used in HSG were excluded from the study. Known cases of pelvic inflammatory disease and those who achieved pregnancy before the performance of hysteroscopy were also excluded from the study.

\section{Results}

A total of 172 women with primary or secondary infertility were enrolled in the study. Out of these, 13 women became pregnant, and two were lost to follow-up and were excluded from our study. Thus, a total of 157 infertile women were analysed. The agreement between HSG and hysteroscopy was $71.3 \%$ for the evaluation of the uterine cavity, and this was considered a fair strength of agreement between the procedures $(\mathrm{k}$ value $=0.302)$.

\section{Conclusion}

Compared to HSG, the incidental findings detected by hysteroscopy amounted to $19.14 \%$. Our study results depict the advantage of hysterolaparoscopy over HSG. Although the sensitivity of HSG is as good as that of diagnostic hysterolaparoscopy for the detection of tubal patency, a significant number of important

Review began 12/22/2020 Review ended 01/02/2021 Published 01/06/2021

\section{() Copyright 2021}

Panda et al. This is an open access article distributed under the terms of the Creative Commons Attribution License CC-BY 4.0., which permits unrestricted use, distribution, and reproduction in any medium, provided the original author and source are credited. incidental findings can be missed by it. Hence, diagnostic hysterolaparoscopy should be offered as the firstline modality for the evaluation of infertility wherever the procedure is available.

\author{
Categories: Obstetrics/Gynecology \\ Keywords: hysterosalpingography, hysterolaparoscopy, chromopertubation., hsg
}

\section{Introduction}

Infertility is a medical condition with significant psychological, social, and medical implications [1,2]. Tubal factor constitutes about 25-30\% whereas uterine factors contribute to around 10-15\% of infertile cases [3,4]. Hysterosalpingography (HSG) is a common radiologic modality employed for the initial workup of female infertile patients to evaluate for tubal patency or any gross intrauterine pathology. HSG is a relatively cheap outpatient procedure, but it bears the risk of radiation exposure. Though pelvic sonography and HSG are thought to be good modalities for evaluating uterine pathology, their ability in evaluating uterine cavity is limited to gross pathologies, and subtle changes in the form of small polyps, adhesions, and subendometrial myomas, which contribute to fertility, can be missed out by these procedures. Hysteroscopy, on the other hand, carries the advantage of having the ability to diagnose such subtle changes because of the magnification it possesses. Although hysterolaparoscopy is costlier and invasive, it is free from radiation exposure and provides a better real-time abdominopelvic view [5-7]. Additionally, hysterolaparoscopy not only detects the abdominopelvic pathologies but also can play a therapeutic role in the same setting $[8,9]$. Despite the above facts, the debate on the role of HSG versus hysteroscopy in the diagnosis and management of infertility still persists. The objective of this study was to evaluate the effectiveness of HSG in diagnosing tubal patency and uterine cavity abnormalities in comparison to diagnostic hysterolaparoscopy and to assess the role of hysterolaparoscopy in the comprehensive workup of infertility, which would help in 


\section{Cureus}

implementing an appropriate management plan for the condition.

\section{Materials And Methods}

The present study was a prospective observational study conducted at the infertility clinic of the Department of Obstetrics and Gynecology, Guru Hospital, Madurai. The study was carried out from February 2018 to January 2019. All infertile women attending our outpatient department (OPD) who were aged between 20-40 years were included in the study. Those who were allergic to the dye used in HSG, those diagnosed with pelvic inflammatory disease or acute vaginal and cervical infection, or those who achieved pregnancy before undergoing hysteroscopy were excluded from our study.

An HSG was considered as normal if the following criteria were fulfilled: normality of uterine cavity; no evidence of tubal block; normal fallopian tube contour; and free bilateral spillage of contrast. HSGs or diagnostic hysterolaparoscopies were performed in all women under aseptic conditions after obtaining the informed written consent. If the HSG was found to be normal, hysteroscopy was performed only if the patient failed to conceive after three ovulation induction cycles. In patients with abnormal HSG findings, hysteroscopy was performed in the immediate postmenstrual phase. If the patient became pregnant within three ovulation induction cycles (before the performance of hysteroscopy), they were excluded from our study.

\section{Sample size calculation and patient enrollment}

Measuring the prevalence of infertility in India as 11\%, with a two-sided significance level of 95\%,and absolute precision of $5 \%$, the sample size was calculated to be 152 [10]. The sample size was calculated using OpenEpi software version 3.01. The sample size was increased to 172 to allow for a potential dropout rate of around 15\%. All HSGs and diagnostic hysterolaparoscopies were performed by specific but different individuals to decrease the chances of interobserver bias. A total of 172 women with primary or secondary infertility was enrolled in the study. Out of these, 13 women became pregnant, and two were lost to followup and were excluded from our study. Thus, a total of 157 infertile women were analysed.

\section{Statistical analysis}

Categorical variables were presented in numbers and percentages (\%). The chi-squared test/Fisher's exact test was used for comparison of qualitative variables, Inter-rater kappa agreement was used to find the strength of agreement between the two methods. All statistical analyses were performed using the SPSS Statistics software version 21.0 (IBM, Armonk, NY).

\section{Results}

A total of 157 subjects were analysed in this study. About $64.9 \%(102 / 157)$ of subjects had primary infertility and $35.1 \%(55 / 157)$ had secondary infertility. The average age and BMI of women in our study were $25.27 \pm 3.96$ years and $25.84 \pm 5.44 \mathrm{Kg} / \mathrm{m}^{2}$, respectively. The mean duration of infertility was $2.90 \pm 1.74$ years. These baseline characteristics are presented in Table 1.

\begin{tabular}{|c|c|c|c|c|}
\hline Type of infertility & Primary infertility & Secondary infertility & P-value & Total cases \\
\hline Number of patients & 102 & 55 & - & 157 \\
\hline Age (years), mean \pm SD & $24.04 \pm 3.91$ & $27.54 \pm 2.92$ & 0.0001 & $25.27 \pm 3.96$ \\
\hline BMI $\left(\mathrm{Kg} / \mathrm{m}^{2}\right)$, mean $\pm \mathrm{SD}$ & $25.43 \pm 5.78$ & $26.61 \pm 4.64$ & 0.1942 & $25.84 \pm 5.44$ \\
\hline Duration of infertility (years), mean $\pm S D$ & $2.88 \pm 1.66$ & $2.94 \pm 1.87$ & 0.8366 & $2.90 \pm 1.74$ \\
\hline
\end{tabular}

TABLE 1: Baseline parameters

SD: standard deviation; BMI: body mass index

Regarding the uterine cavity findings, HSG was normal in 120 (76.43\%) women and abnormal in 37 (23.57\%) women; 105 (66.8\%) women were found to have normal hysteroscopic findings and 52 women (33.2\%) had abnormal hysteroscopic findings. A summary of the hysteroscopic and HSG findings is presented in Table 2. 


\section{Cureus}

\begin{tabular}{|c|c|c|c|c|c|}
\hline Hysteroscopic findings & $\begin{array}{l}\text { Number of patients } \\
\text { ( } n=157)\end{array}$ & $\begin{array}{l}\text { Percentage } \\
\text { (\%) }\end{array}$ & HSG findings & $\begin{array}{l}\text { Number of patients } \\
\text { ( } n=157)\end{array}$ & $\begin{array}{l}\text { Percentage } \\
\text { (\%) }\end{array}$ \\
\hline Normal cavity & 105 & 66.8 & Normal & 120 & 76.4 \\
\hline Abnormal & 52 & 33.2 & Abnormal & 37 & 23.6 \\
\hline Complete uterine septum & 4 & 2.54 & Filling defects & 17 & 10.8 \\
\hline Partial septum & 10 & 6.3 & Irregular cavity & 12 & 7.64 \\
\hline Asherman's syndrome & 7 & 4.45 & Arcuate uterus & 2 & 1.27 \\
\hline Bilateral ostia fibrosis & 8 & 5.08 & $\begin{array}{l}\text { Bicornuate } \\
\text { uterus }\end{array}$ & 9 & 5.73 \\
\hline Unilateral fibrosis & 4 & 2.54 & Small cavity & 4 & 2.54 \\
\hline Endometrial polyp & 10 & 6.3 & & & \\
\hline Polypoidal endometrium & 5 & 3.15 & & & \\
\hline $\begin{array}{l}\text { Atrophic or pale } \\
\text { endometrium }\end{array}$ & 11 & 7 & & & \\
\hline Submucosal fibroid & 4 & 2.54 & & & \\
\hline Endocervical polyp & 2 & 1.27 & & & \\
\hline Cervical stenosis & 12 & 7.64 & & & \\
\hline
\end{tabular}

\section{TABLE 2: Evaluation of uterine cavity by HSG and hysteroscopy}

HSG: hysterosalpingography

The comparison of uterine cavity findings on HSG and hysteroscopy is shown in Table 3. The sensitivity, specificity, positive predictive value, and negative predictive value were $42.3 \%, 85.7 \%, 59.45 \%$, and $75 \%$ respectively. The agreement between HSG and hysteroscopy was $71.3 \%$. This was statistically significant ( $\mathrm{p}-$ value $=0.002$ ) with a fair strength of agreement between the two procedures [ $\mathrm{k}$ value $=0.302$; standard error (SE) of kappa $=0.080,95 \%$ CI: from 0.145 to 0.460$]$.

\begin{tabular}{|c|c|c|c|c|c|c|}
\hline & & \multicolumn{2}{|c|}{ Uterine cavity findings on hysteroscopy } & \multirow[t]{2}{*}{ Total } & P-value & Kappa \\
\hline & & Abnormal & Normal & & \multirow{4}{*}{0.0002} & \multirow{4}{*}{0.302} \\
\hline \multirow{2}{*}{ Uterine cavity findings on HSG } & Abnormal & 22 (TP) & $15(\mathrm{FP})$ & 37 & & \\
\hline & Normal & 30 (FN) & 90 (TN) & 120 & & \\
\hline Total & & 52 & 105 & & & \\
\hline
\end{tabular}

\section{TABLE 3: Comparison of uterine cavity findings on HSG and hysteroscopy}

Sensitivity $=42.3 \%$; specificity $=85.7 \%$; positive predictive value $=59.45 \%$; negative predictive value $=75 \%$; $k$ appa $=0.302$; standard error of kappa $=0.080 ; 95 \% \mathrm{Cl}$ : from 0.145 to 0.460 ; strength of agreement is considered to be fair

TP: true positive; TN: true negative; FP: false positive; FN: false negative; HSG: hysterosalpingography

A summary of the diagnostic hysterolaparoscopic findings is presented in Table 4. The tubal block was found in $38.2 \%$ of cases of primary infertility and $36.36 \%$ cases of secondary infertility. 


\section{Cureus}

\begin{tabular}{|c|c|c|c|c|}
\hline Findings & Primary infertility $(n=102)$ & Percentage (\%) & Secondary infertility $(n=55)$ & Percentage (\%) \\
\hline Tubal block & 39 & 38.2 & 20 & 36.36 \\
\hline Tubal adhesions & 10 & 9.8 & 12 & 21.81 \\
\hline Tubo-ovarian mass & 2 & 1.9 & 8 & 14.54 \\
\hline Endometriosis & 14 & 13.72 & 10 & 18.18 \\
\hline PID & 11 & 10.78 & 15 & 27.27 \\
\hline Pelvic adhesions & 10 & 9.8 & 14 & 25.45 \\
\hline
\end{tabular}

\section{TABLE 4: Diagnostic hysterolaparoscopy findings}

PID: pelvic inflammatory disease

The comparison of tubal status on HSG and diagnostic hysterolaparoscopy is shown in Table 5. The sensitivity, specificity, positive predictive value, and negative predictive value were $100 \%, 84.4 \%, 69.4 \%$, and $100 \%$ respectively. The agreement between HSG and hysteroscopy was $88.5 \%$. This was statistically significant ( $\mathrm{p}$-value $=0.0001$ ) with a good strength of agreement between the two procedures $(\mathrm{k}$ value $=0.74$; SE of kappa $=0.056,95 \% \mathrm{CI}$ : from 0.631 to 0.841 ).

\begin{tabular}{|c|c|c|c|c|c|c|}
\hline & & \multicolumn{2}{|c|}{ Tubal findings on hysteroscopy } & \multirow[t]{2}{*}{ Total } & P-value & Kappa \\
\hline & & Abnormal & Normal & & \multirow{4}{*}{0.0001} & \multirow{4}{*}{0.74} \\
\hline \multirow{2}{*}{ Tubal findings on HSG } & Abnormal & 41 (TP) & $18(\mathrm{FP})$ & 59 & & \\
\hline & Normal & $0(\mathrm{FN})$ & $98(\mathrm{IN})$ & 98 & & \\
\hline Total & & 41 & 116 & 157 & & \\
\hline
\end{tabular}

\section{TABLE 5: Comparison of tubal patency detection on HSG and combined hysterolaparoscopy}

Sensitivity $=100 \%$; specificity $=84.4 \%$; positive predictive value $=69.4 \%$; negative predictive value $=100 \%$; Kappa=0.74; Standard error of kappa $=0.056,95 \% \mathrm{Cl}$ : from 0.631 to 0.841 ; the strength of agreement is considered to be good

TP: true positive; TN: true negative; FP: false positive; FN: false negative; HSG: hysterosalpingography

\section{Discussion}

In this study, we compared HSG with hysteroscopy considering uterine cavity and tubal factors separately. We found a fair strength of agreement for uterine cavity findings, whereas the strength of agreement between the two modalities was good for detecting the tubal blockage. HSG was normal in $76.43 \%$ of women and abnormal in $23.57 \%$. Ibinaiye et al. [11] also found similar results (normal uterine cavity on HSG in 75.9\% and abnormal in 24.1\%). Chauhan et al. [12] and Vaid et al. [13] have reported a detection rate of $13 \%$ and $8.29 \%$ for abnormal uterine cavities on HSG. The most common abnormal uterine cavity finding on HSG in our study was filling defects (10.8\%) followed by irregular uterine cavities (7.64\%). Out of 157 women who underwent the hysteroscopic procedure, $66.8 \%$ were found to have normal hysteroscopic findings, with $33.2 \%$ of women having abnormal results. Wadhwa et al. [10] found abnormal findings in $35.51 \%$ whereas Chauhan et al. [12] reported abnormal findings in $20 \%$ of cases.

In the present study, the agreement between the two procedures was $71.3 \%$ for uterine cavity findings. In terms of comparison, the difference in findings between HSG and hysteroscopy was statistically significant ( $p$-value $=0.001$ ) with a fair degree of agreement between the two procedures ( $k$ value $=0.302)$. This means that a significant number of abnormal uterine cavity (around 29.7\%) findings can be missed on HSG. Similar results were obtained in a recent study conducted by Wadhwa et al. [10], with $75 \%$ agreement between the two procedures.

There are varying data regarding the sensitivity and specificity of HSG in detecting uterine cavity 
abnormalities in different studies [8,14-15]. Thus, the sensitivity and specificity appear to range between 2181 and 70-98\%, respectively. Taşkın et al. [16] found a low sensitivity n their study, but this could be due to the fact that the male partners in most of the couples visiting their clinic had male factor infertility. The study by Nigam et al. [17] reported a positive predictive value of $70 \%$ with a false-negative rate of $12.96 \%$.

We found incidental findings detected by hysteroscopy in $19.14 \%$ of cases. These incidental findings might have detrimental effects on fertility, and most of them such as partial septum, endometrial polyp, etc, could be easily treated by hysteroscopy. Other studies also found hysteroscopically detected incidental findings in $15.38 \%$ [10], 29.2\% [16], 32.12\% [13], and 13\% [12] of cases.

Hysterolaparoscopy holds the advantage of being both a diagnostic and therapeutic procedure in various abdominopelvic pathologies including tubal pathologies. In the present study, we assessed the tubal patency in the female infertile patients by performing chromopertubation. We also compared the HSG with hysterolaparoscopy as the reference standard. We found a sensitivity of $100 \%$ and a specificity of $84.4 \%$ for the detection of tubal patency on HSG. Similarly, Agrawal et al. [18] found the sensitivity and specificity of HSG to be $100 \%$ and $52.31 \%$ respectively. On comparing the same parameters, Vaid et al. found a sensitivity of $80.6 \%$ and specificity of $81.5 \%$ for HSG. They found that the agreement between the two modalities was 74\% [13]. Agrawal et al. [18] and Tognil et al. [19] found the probability of tubal occlusion on

hysterolaparoscopy to be very low while HSG was normal. Similar results were found in the present study in that no patient showed tubal blockage on chromopertubation when HSG was reported to have tubal spillage of dye.

\section{Study limitations and observations on future research}

The only limitation of this study is that parameters indicating the success of fertility treatment such as clinical pregnancy rate and live birth rates were not studied in relation to hysterolaparoscopic findings. However, this is a separate domain and future research should be aimed at studying the correlation between hysterolaparoscopic findings and parameters such as clinical pregnancy rate and live birth rates, etc.

\section{Conclusions}

Our study results illustrate the advantage of hysterolaparoscopy over HSG. Although the sensitivity of HSG is as good as that of diagnostic hysterolaparoscopy for the detection of tubal patency, a significant number of incidental findings can be missed by the procedure. Moreover, diagnostic hysterolaparoscopy holds the advantage of providing the details of other abdominopelvic pathologies, and it can also provide therapeutic intervention in the same setting. Hence, diagnostic hysterolaparoscopy should be offered as the first-line modality for the evaluation of infertility wherever the procedure is available. An abnormal HSG should always be confirmed with a hysterolaparoscopy.

\section{Additional Information}

\section{Disclosures}

Human subjects: Consent was obtained by all participants in this study. Animal subjects: All authors have confirmed that this study did not involve animal subjects or tissue. Conflicts of interest: In compliance with the ICMJE uniform disclosure form, all authors declare the following: Payment/services info: All authors have declared that no financial support was received from any organization for the submitted work. Financial relationships: All authors have declared that they have no financial relationships at present or within the previous three years with any organizations that might have an interest in the submitted work. Other relationships: All authors have declared that there are no other relationships or activities that could appear to have influenced the submitted work.

\section{References}

1. Baghianimoghadam MH, Aminian AH, Baghianimoghadam B, Ghasemi N, Abdoli AM, Seighal Ardakani N, Fallahzadeh H: Mental health status of infertile couples based on treatment outcome . Iran J Reprod Med. 2013, 11:503-10.

2. Ahmadi Forooshany SH, Yazdkhasti F, Safari Hajataghaie S, Nasr Esfahani MH: Infertile individuals' marital relationship status, happiness, and mental health: a causal model. Int J Fertil Steril. 2014, 8:315-24.

3. Honoré GM, Holden AE, Schenken RS: Pathophysiology and management of proximal tubal blockage . Fertil Steril. 1999, 71:785-95. 10.1016/s0015-0282(99)00014-X

4. Al-Inany H: Female infertility. Clin Evid. 2005, 2005:0819.

5. Onwuchekwa CR, Oriji VK: Hysterosalpingographic (HSG) pattern of infertility in women of reproductive age. J Hum Reprod Sci. 2017, 10:178-84. 10.4103/jhrs.JHRS_121_16

6. Kamel RM: Management of the infertile couple: an evidence-based protocol . Reprod Biol Endocrinol. 2010, 8:21. 10.1186/1477-7827-8-21

7. Chalazonitis A, Tzovara I, Laspas F, Porfyridis P, Ptohis N, Tsimitselis G: Hysterosalpingography: technique and applications. Curr Probl Diagn Radiol. 2009, 38:199-205. 10.1067/j.cpradiol.2008.02.003

8. Nayak PK, Mahapatra PC, Mallick J, Swain S, Mitra S, Sahoo J: Role of diagnostic hystero-laparoscopy in the evaluation of infertility: A retrospective study of 300 patients. J Hum Reprod Sci. 2013, 6:32-4. 


\section{Cureus}

10.4103/0974-1208.112378

9. Zhang E, Zhang Y, Fang L, Li Q, Gu J: Combined hysterolaparoscopy for the diagnosis of female infertility: a retrospective study of 132 patients in china. Mater Sociomed. 2014, 26:156-7. 10.5455/msm.2014.26.156157

10. Wadhwa L, Rani P, Bhatia P: Comparative prospective study of hysterosalpingography and hysteroscopy in infertile women. J Hum Reprod Sci. 2017, 10:73-8. 10.4103/jhrs.JHRS_123_16

11. Ibinaiye PO, Reuben OL, Avidime S: Comparative evaluation of pattern of abnormalities in hysterosalpingography, diagnostic laparoscopy and hysteroscopy among women with infertility in Zaria, Nigeria. Int J Med Med Sci. 2015, 7:26-35. 10.5897/IJMMS2014.1106

12. Chauhan MB, Lakra P, Nanda S, Malik R, Malhotra V: Hysterosalpingography vs hysteroscopy: role in assessment of uterine factor during infertility workup. J S Asian Fed Obstet Gynaecol. 2013, 5:116-9.

13. Vaid K, Mehra S, Verma M, Jain S, Sharma A, Bhaskaran S: Pan endoscopic approach "hysterolaparoscopy" as an initial procedure in selected infertile women. J Clin Diagn Res. 2014, 8:95-8.

10.7860/JCDR/2014/7271.4018

14. Vahdat M, Sariri E, Kashanian M, et al.: Can combination of hysterosalpingography and ultrasound replace hysteroscopy in diagnosis of uterine malformations in infertile women?. Med J Islam Repub Iran. 2016, 30:352.

15. Sahu L, Tempe A, Gupta S: Hysteroscopic evaluation in infertile patients: a prospective study . Int J Reprod Contracept Obstet Gynecol. 2012, 1:37-41. 10.5455/2320-1770.ijrcog001512

16. Taşkın EA, Berker B, Ozmen B, Sönmezer M, Atabekoğlu C: Comparison of hysterosalpingography and hysteroscopy in the evaluation of the uterine cavity in patients undergoing assisted reproductive techniques. Fertil Steril. 2011, 96:349-52. 10.1016/j.fertnstert.2011.05.080

17. Nigam A, Saxena P, Mishra A: Comparison of hysterosalpingography and combined laparohysteroscopy for the evaluation of primary infertility. Kathmandu Univ Med J (KUMJ). 2015, 13:281-5. 10.3126/kumj.v13i4.16824

18. Agrawal N, Fayyaz S: Can hysterolaparoscopic mediated chromopertubation obviate the need for hysterosalpingography for proximal tubal blockage?: An experience at a single tertiary care center. J Gynecol Obstet Hum Reprod. 2019, 48:241-5. 10.1016/j.jogoh.2018.04.011

19. Togni R, Benetti-Pinto CL, Yela DA: The role of diagnostic laparoscopy in gynecology . Sao Paulo Med J. 2016, 134:70-3. 10.1590/1516-3180.2014.00241501 